\title{
Usefulness of a Serological Panel Test in the Assessment of Gastritis in Symptomatic Children
}

\author{
Gian Luigi de Angelis $^{a} \quad$ Lucas Giovanni Cavallaro $^{b}$ Valentina Maffini ${ }^{a}$ \\ Ali Mahamat Moussab ${ }^{b}$ Fabiola Fornaroli ${ }^{a}$ Stefania Liatopoulou ${ }^{b}$ \\ Barbara Bizzarria $^{\mathrm{a}}$ Roberta Merli ${ }^{\mathrm{b}}$ Giuseppe Comparato ${ }^{\mathrm{b}}$ Pietro Caruana $^{\mathrm{c}}$ \\ Giulia Martina Cavestro $^{\mathrm{b}}$ Angelo Franzéd $^{\mathrm{d}}$ Francesco Di Mario $^{\mathrm{b}}$ \\ Departments of a Paediatrics and ${ }^{\mathrm{b}}$ Clinical Sciences, ${ }^{\mathrm{c} C}$ Chair of Pathology, University of Parma, and \\ ${ }^{\mathrm{d}}$ Gastroenterology Unit, Azienda Universitaria Ospedaliera di Parma, Parma, Italy
}

\section{Key Words}

IgG anti-H. pylori antibodies · Serum pepsinogens I and II •

Gastrin-17 · Helicobacter pylori $\cdot$ Gastritis

\begin{abstract}
Background: Non-invasive methods are advisable for the detection of Helicobacter pylori-related chronic gastritis in pediatric patients. Serum pepsinogens I and II (sPGII and sPGII), gastrin-17 (G-17) and anti-H. pylori antibodies (lgG-Hp) have been proposed as a 'serological gastric biopsy'. Aim: To assess $H$. pylori infection and to evaluate gastric mucosa status in a pediatric population by means of serological parameters such as sPGI, sPGII, G-17 and IgG-Hp. Methods: 45 consecutively children evaluated for upper gastrointestinal symptoms were analyzed. All children were submitted to upper gastrointestinal endoscopy with biopsies. Serum samples were analyzed for IgG-Hp, sPGII, sPGI and G-17 (Biohit, Helsinki, Finland). Results: 18 children had H. pylori-related mild or moderate non-atrophic chronic gastritis. They presented significantly higher mean levels of sPGII and of $\mathrm{IgG}-\mathrm{Hp}$ than negative ones, either under or up to 10 years. sPGl showed significantly increased levels in $\mathrm{H}$. pylori-positive patients only over 10 years. G-17 levels were not differ-
\end{abstract}

ent between $H$. pylori-positive and -negative ones. The best cut-offs of IgG-Hp, sPGII and of product IgG-Hp.sPGII, to identify H. pylori infection, were $30 \mathrm{IU} / \mathrm{l}, 9 \mu \mathrm{g} / \mathrm{l}$, and $241 \mathrm{IU} /$ $1 \cdot \mu \mathrm{g} / \mathrm{l}$, respectively. The product IgG-Hp.sPGIl identified $H$. pylori infection with a $100 \%$ sensitivity, $92 \%$ specificity, $90 \%$ positive predictive value and $100 \%$ negative predictive value. IgG- $\mathrm{Hp}$ and IgG- $\mathrm{Hp}$ showed a correlation $(r=0.94 ; \mathrm{p}<$ 0.001). Conclusions: Combined analysis of sPGIl and IgG-Hp antibody levels could be recommended as a non-invasive panel for the assessment of $H$. pylori-related histological alterations of gastric mucosa in childhood.

Copyright $\odot 2007$ S. Karger AG, Basel

\section{Introduction}

Helicobacter pylori infection is known to be acquired primarily during childhood [1]. In the last 30 years, the prevalence of this infection has dramatically changed in developed countries, with a marked decrease of infected children ( $<10 \%$ in some countries) by the age of 10 years, remaining very high in developing countries (up to $80 \%$ of infected children $<5$ years) [2]. However, this prevalence is quite elevated (ranging from 22 to $45 \%$ ) also in

\section{KARGER \\ Fax +4161306 1234 \\ E-Mail karger@karger.ch}

www.karger.com
(C) 2007 S. Karger AG, Basel

0257-2753/07/0253-0206\$23.50/0

Accessible online at: www.karger.com/ddi
Prof. Francesco Di Mario

Department of Clinical Sciences, University of Parma, Maggiore Hospital via A. Gramsci 14, IT-43100 Parma (Italy)

E-Mail francesco.dimario@unipr.it 
developed countries, when a population of symptomatic children is considered $[3,4]$.

In both adults and children $[5,6], H$. pylori infection is responsible for the majority of chronic gastritis and its action predispose to severe diseases such as peptic ulcer and gastric malignancies. Ulcer disease is prevalently related to $H$. pylori infection, although it develops in a small number of infected children [7]. The infection is, also, a risk factor for mucosa-associated lymphoid tissue (MALT) lymphoma both in adults and children as well for primary gastric cancer in adults [8]. Moreover, early acquisition of the infection is considered a risk factor for development of gastric cancer in adulthood [9]. On the other hand, the role of $H$. pylori in children with recurrent abdominal pain or non-ulcer dyspepsia remains unclear [10-13].

According to international guidelines $[6,14,15]$, in children with severe upper gastrointestinal symptoms, endoscopy with biopsies is the gold standard to diagnose organic disease and $H$. pylori infection. On the other side, a non-invasive test is proposed in epidemiologic studies, in efficacy monitoring of $H$. pylori treatment and in patients who refuse endoscopy.

Among the available non-invasive tests, the most current used are: detection of $H$. pylori antibodies from different substrates (serum, saliva and urine), stool antigen research and ${ }^{13} \mathrm{C}$-urea breath test. Enzyme-linked immunosorbent assays, to detect $H$. pylori antibodies in whole blood, plasma and serum, are relatively inexpensive and easy to perform. However, compared with histology, they have not sufficiently high sensitivity and specificity both in adults and children and are not recommended as a unique means of diagnosing $H$. pylori infection [14]. In young children the serologic response may be weak or absent $[16,17]$. Furthermore, it does not distinguish between actual and previous infection because the antibody titer decreases very slowly after cure [18]. False-positives may also occur after spontaneous [19] or previous eradication [20].

$H$. pylori stool antigen test is validated to screen for $H$. pylori infection in adults [5] and it is promising in children [21], particularly if the new monoclonal enzyme immunoassay [22] is used. However, additional pediatric studies evaluating the accuracy of this test are required $[23,24]$. The ${ }^{13} \mathrm{C}-\mathrm{UBT}$ has excellent performance both in adults [25] and children [26]. However, the results could be influenced by concurrent use of drugs (antimicrobials or gastric antisecretory) or by the presence of other urease-producing organisms. This test, moreover, is expensive and requires air sampling with a facemask, which is technically more difficult to perform and potentially unpleasant in young children. Finally, the ${ }^{13} \mathrm{C}$-urea breath test has not been validated in a sufficient number of young children (especially $<2$ years of age) [27].

No single test, either invasive or non-invasive, is fully reliable, and even histology is not positive in $100 \%$ of cases [28]. Furthermore, all of the non-invasive tests do not give any information about morphological and functional status of gastric mucosa.

Morphological abnormalities of the gastric mucosa may be associated with various disturbances of gastric secretion. Indeed, prior to the discovery of $H$. pylori, Samloff et al. [29] reported that the inflammation of the gastric mucosa was associated with alterations in pepsinogens I and II secretion. It is well known that serum pepsinogen I (sPGI) and II (sPGII) increase in H. pylorirelated non-atrophic chronic gastritis in adults $[30,31]$ as well in children $[32,33]$ and their concentrations decrease after eradication therapy [34-36]. In particular, sPGII seems to better correlate with the severity of inflammation $[33,34,37]$. Conversely, very low values of sPGI associated with altered levels of G-17 (increased or decreased) are well demonstrated in adults to be correlated with atrophic damages of gastric mucosa [38]. These pathologic features are rare in children $[39,40]$, although their presence is not completely excluded in a pediatric population, as observed in some recent studies [41, 42]. Therefore, a panel of four serological tests such as sPGI, sPGII, gastrin-17 (G-17) and anti-H. pylori antibodies (IgG-Hp) could be proposed in the first evaluation of children with upper gastrointestinal symptoms as performed by Kalach et al. [43].

The aim of the present study was to evaluate, in a population of children, $H$. pylori infection and gastric mucosa status by means of serological parameters such as sPGI, sPGII, G-17, and IgG-Hp, and to explore the accuracy of these tests in comparison to endoscopy with biopsy.

\section{Materials and Methods}

A series of 45 consecutive children ( 19 males, 26 females, mean age 10.4, range 3-17 years) were referred to Department of Pediatrics, University of Parma, Parma, Italy, for epigastric pain associated or not with vomiting. None of the children had been previously treated for $H$. pylori infection or had taken antibiotics, acid-suppressive drugs $\left(\mathrm{H}_{2}\right.$-receptor, proton pump inhibitors, antacids, bismuth preparations) within the previous month. Children with celiac disease, renal failure or gastric surgery were excluded from the study. Informed consent was obtained from the parents. 
Assessment of H. pylori Status

At baseline, each patient underwent upper gastrointestinal endoscopy with 6 biopsies for histological examination (3 from the antrum, 3 from the corpus), 1 for microbiological analysis and 1 for the rapid urease test. Serial sections (5 $\mu \mathrm{m}$ thick) prepared from formalin-fixed biopsy samples were embedded in paraffin and stained with hematoxylin and eosin for conventional histological analysis and with modified Giemsa for the detection of $H$. pylori. The Updated Sydney System classification was used to assess the grade of gastritis [44]. The rapid urease test (Helori Urease, Eurospital, Trieste, Italy) was performed with antrum samples; the reaction was considered positive when the reagent turned from yellow to red magenta, thus indicating the presence of $H$. pylori. For culture, mucosal biopsies from antrum were placed on agar plates and incubated at $37^{\circ} \mathrm{C}$ with $5 \% \mathrm{CO}_{2}$ and $100 \%$ humidity for 7 days. The H. pylori status was assessed by at least two positive tests: histology, rapid urease test (CLO test) and culture.

Determination of sPGI, sPGII, G-17 and IgG-Hp Levels

Blood samples ( $5 \mathrm{ml}$ venous blood) were taken from each child on the first day of examination prior to endoscopy. These samples were stored before analysis and then centrifuged at $-20^{\circ} \mathrm{C}$. sPGI, sPGII, serum G-17 and IgG-Hp levels were determined with enzyme-linked immunosorbent assays (Biohit, Helsinki, Finland), according to the manufacturer's instructions.

\section{Statistical Analysis}

Values of the parameters examined and age were compared according to the $H$. pylori infection, endoscopical and histological findings by means of Mann-Whitney rank-sum test. $\chi^{2}$ was used to compare qualitative variables. The diagnostic accuracy of serological parameters for identifying $H$. pylori infection was determined with receiving operating characteristic (ROC) curves; patients were subdivided as: $\mathrm{a}=$ true-positive, $\mathrm{b}=$ false-positive, $\mathrm{c}=$ false-negative, and $d=$ true-negative. Sensitivity: $a /(a+c)$, specificity: $d /(b+d)$, positive predictive value: $a /(a+b)$, negative predictive value: $d /(c+d)$ and overall accuracy: $(a+d) /(a+c+b+d)$ were computed. Spearman rank correlation for comparisons between IgG-Hp, sPGII and IgG-Hp·sPGII was applied.

For all calculations, Number Cruncher Statistical Systems (NCSS Software 2000 Version, Utah, USA) software was used.

\section{Results}

\section{Characteristics of Patients}

No statistically significant differences in sex and age were found between $H$. pylori-positive and -negative children. Eighteen children were $H$. pylori-positive (40\%, 10 females, mean age $10.4 \pm 3$ years, range $5-17)$ and 27 were $H$. pylori-negative $(60 \%, 16$ females, mean age $10.5 \pm 3$, range $3-16)$. Infection was detected by all the diagnostic tests (CLO test, culture and histology) in 10 patients (55.6\%), by both histology and CLO test in 6 patients (33.4\%), by both endoscopy and culture in 1 patient $(5.5 \%)$, and by both CLO test and culture in 1 child (5.5\%).
Table 1. Endoscopic findings according to H. pylori infection

$\begin{array}{ll}\text { H. pylori-positive } & \text { H.pylori-negative } \\ (\mathrm{n}=18) & (\mathrm{n}=27)\end{array}$

$\begin{array}{lrr}\text { Esophagitis } & 0 & 8 \\ \text { Antral nodular gastritis* }^{*} & 16 & 2 \\ \text { Duodenitis, superficial } & 1 & 2 \\ \text { Duodenitis, erosive } & 3 & 1 \\ \text { Antral erythema } & 1 & 5 \\ \text { Hemorrhagic gastritis } & 0 & 1 \\ \text { Normal } & 0 & 14\end{array}$

$\chi^{2}$ test. ${ }^{*} \mathrm{p}<0.05$ for comparison between $H$. pylori-positive and $H$. pylori-negative patients.

The endoscopic findings of $H$. pylori-positive and -negative children are summarized in table 1 . Antral nodular gastritis was significantly associated with $H$. pyloripositive patients (16 out of 18 patients, $89 \%$ ) in comparison to $H$. pylori-negative ones ( 2 out of $27,7 \%, p<0.001$ ).

\section{Histopathology}

All $H$. pylori-positive children had mild to moderate active chronic gastritis; 2 children also demonstrated lymphoid nodular hyperplasia. In $H$. pylori-negative patients, 25 had normal gastric mucosa, and 2 had antral chronic gastritis.

\section{Serological Tests}

Children with $H$. pylori-related gastritis had significantly both higher sPGII $(12.2 \pm 5.3 \mu \mathrm{g} / \mathrm{l})$ levels and $\operatorname{IgG}$ anti- $H p$ antibody titers ( $66 \pm 31 \mathrm{IU} / \mathrm{l})$ as well as the product IgG-Hp·sPGII $(865 \pm 862 \mathrm{IU} / \mathrm{l} \cdot \mu \mathrm{g} / \mathrm{l})$ and a significantly lower sPGI/sPGII ratio $(8 \pm 2.3)$ than the $H$. $p y$ lori-negative ones (sPGII $5.8 \pm 2.4 \mu \mathrm{g} / \mathrm{l}, \mathrm{p}<0.01$; IgG-Hp $15 \pm 13 \mathrm{IU} / \mathrm{l}, \mathrm{p}<0.001$; IgG-Hp•sPGII $87 \pm 80 \mathrm{IU} / \mathrm{l} \cdot$ $\mu \mathrm{g} / \mathrm{l}, \mathrm{p}<0.001$; sPGI/sPGII ratio $14 \pm 7, \mathrm{p}<0.001)$. sPGI levels were also higher in $H$. pylori-positive children (91 $\pm 34 \mu \mathrm{g} / \mathrm{l})$ than in $H$. pylori-negative children $(72 \pm 26$ $\mu \mathrm{g} / \mathrm{l})$, but this finding was not statistically significant. Mean G-17 serum values were similar in $H$. pylori-positive $(8.2 \pm 6.5 \mathrm{pg} / \mathrm{l})$ and $H$. pylori-negative children $(8.9$ $\pm 7 \mathrm{pg} / \mathrm{l})$. These data are shown in figure 1 .

IgG-Hp and sPGII were significantly correlated with each other $(r=0.60, p<0.001)$; however, a very high positive correlation was observed between IgG-Hp and IgG$H p \cdot$ sPGII $(\mathrm{r}=0.94, \mathrm{p}<0.001)$.

$H$. pylori-positive children $\geq 10$ years of age (11 children, mean age 13 years) had significantly increased lev- 
Fig. 1. sPGI, sPGII, sG-17, sPGI/sPGII, IgG-Hp and IgG-Hp•sPGII according to H. pylori infection.

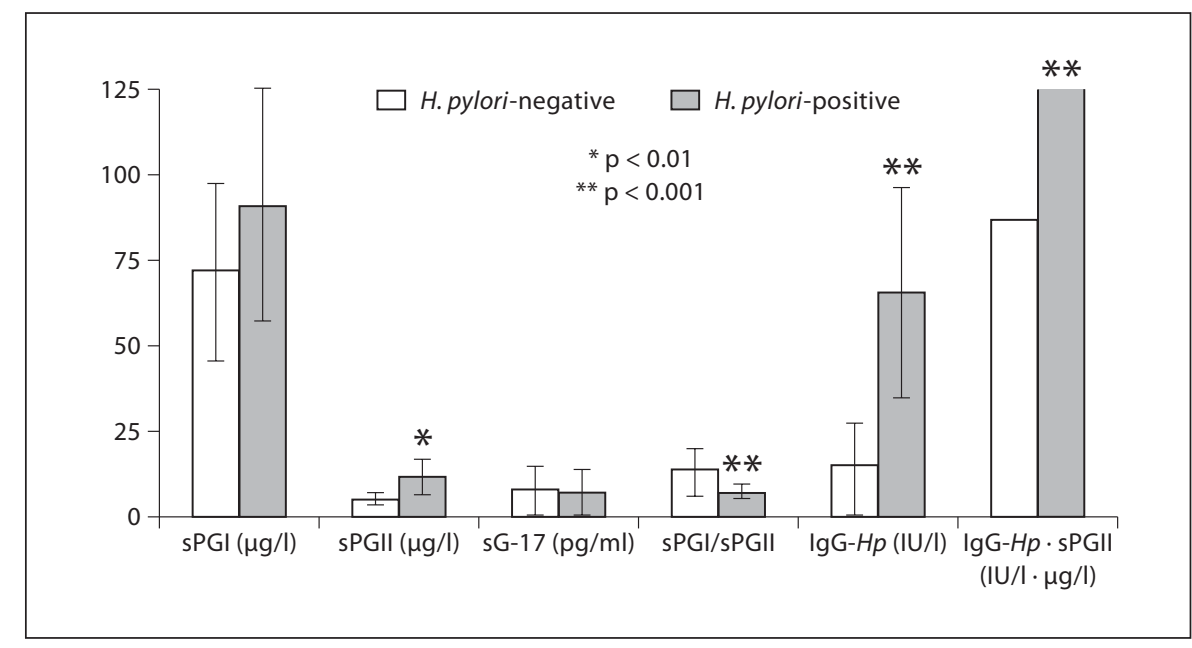

Table 2. sPGI, sPGII, sPGI/sPGII, sG-17 and IgG anti-Hp antibodies according to H. pylori infection and age (over or less 10 years)

\begin{tabular}{|c|c|c|c|c|}
\hline & \multicolumn{2}{|c|}{ H. pylori-positive $(\mathrm{n}=18)$} & \multicolumn{2}{|c|}{ H. pylori-negative $(\mathrm{n}=27)$} \\
\hline & $\begin{array}{l}\geq 10 \text { years } \\
(\mathrm{n}=11)\end{array}$ & $\begin{array}{l}<10 \text { years } \\
(\mathrm{n}=7)\end{array}$ & $\begin{array}{l}\geq 10 \text { years } \\
(\mathrm{n}=15)\end{array}$ & $\begin{array}{l}<10 \text { years } \\
(\mathrm{n}=12)\end{array}$ \\
\hline sPGI, $\mu \mathrm{g} / 1$ & $102.3 \pm 36.5^{1}$ & $72.2 \pm 21.9$ & $69.6 \pm 24.6^{1}$ & $75.5 \pm 28.5$ \\
\hline sPGII, $\mu \mathrm{g} / \mathrm{l}$ & $13.8 \pm 1.0^{1}$ & $9.7 \pm 2.5^{2}$ & $5.9 \pm 2.9^{1}$ & $5.6 \pm 1.5^{2}$ \\
\hline $\mathrm{sG}-17, \mathrm{pg} / \mathrm{ml}$ & $6.0 \pm 3.8$ & $11.5 \pm 8.6$ & $6.1 \pm 4.5$ & $12.4 \pm 20$ \\
\hline sPGI/sPGII & $8.1 \pm 2.6^{1}$ & $7.6 \pm 2.1^{2}$ & $13.9 \pm 6.6^{1}$ & $14.4 \pm 7.3^{2}$ \\
\hline IgG-Hp, IU/l & $75.9 \pm 33.8^{1}$ & $49.7 \pm 18.9^{2}$ & $14.4 \pm 12.6^{1}$ & $15.5 \pm 14.8^{2}$ \\
\hline IgG-Hp sPGII & $1,110.5 \pm 1,030.9^{1,3}$ & $478.4 \pm 225.7^{2,3}$ & $93.3 \pm 72.9^{1}$ & $86.7 \pm 81^{2}$ \\
\hline
\end{tabular}

Mann-Whitney U test. ${ }^{1} \mathrm{p}<0.05$ for comparison between patients $\geq 10$ years. ${ }^{2} \mathrm{p}<0.05$ for comparison between patients $<10$ years. ${ }^{3}$ For comparison between $H$. pylori-positive patients. els of both sPGI and sPGII and $H$. pylori antibodies as well as a significantly lower sPGI/sPGII ratio than the $H$. pylori-negative children of this age group.

In patients $<10$ years of age, the $H$. pylori-positive group ( 7 children, mean age 7.4 years) demonstrated significantly higher levels of $H$. pylori antibodies, sPGII, IgG-Hp•sPGII and a significantly lower sPGI/sPGII ratio than $H$. pylori-negative children (14 children, mean age 8.3 years). No significant difference was found in both sPGI and G-17.

H. pylori-positive children $\geq 10$ years of age had a higher trend of antibody and serum pepsinogen values than positive children $<10$ years of age, although this finding was not statistically significant. However, among $H$. pylori-positive children, mean IgG $\cdot$ sPGII resulted being significantly higher in patients $>10$ years than in those $<10$ years. Among $H$. pylori-negative children, there were no differences between children older or younger than 10 years for all the serological parameters considered. These data are summarized in table 2.

Finally, among $H$. pylori-positive patients, those with antral nodular gastritis (16 out of 18) had a higher trend of both sPGI $(92.5 \pm 36 \mu \mathrm{g} / \mathrm{l})$ and sPGII $(12.5 \pm 5.7$ $\mu \mathrm{g} / \mathrm{l})$ levels than those without this endoscopic picture (sPGI $60 \pm 41 \mu \mathrm{g} / \mathrm{l}$, sPGII $6.9 \pm 4.8 \mu \mathrm{g} / \mathrm{l}$ ), although without a significant difference $(\mathrm{p}=0.39$ and $\mathrm{p}=0.12$, respectively, for sPGII and sPGI). sPGI/sPGII and G-17 were similar in $H$. pylori-positive patients with (sPGI/ sPGII $7.9 \pm 41 \mu \mathrm{g} / \mathrm{l}$ and G-17 $8 \pm 41 \mu \mathrm{g} / \mathrm{l}$ ) or without antral nodular gastritis (sPGI/sPGII $8.8 \pm 0.31 \mu \mathrm{g} / \mathrm{l}$ and G-17 $6 \pm 4.9 \mu \mathrm{g} / \mathrm{l}, \mathrm{p}=0.12$ and $\mathrm{p}=0.77)$. 
Table 3. Performance characteristics of IgG-Hp, sPGII and sPGII·IgG to discriminate for $H$. pylori infection according to the best cutoffs calculated by means of ROC curves

\begin{tabular}{|c|c|c|c|c|c|}
\hline & Overall accuracy & Sensitivity & Specificity & PPV & NPV \\
\hline IgG-Hp > 30 IU/1 (95\% CI) & $93(84-99)$ & $94(75-100)$ & $92(73-98)$ & $89(68-99)$ & $96(77-100)$ \\
\hline sPGII >9 $\mu \mathrm{g} / \mathrm{l}(95 \% \mathrm{CI})$ & $87(72-94)$ & $78(56-94)$ & $92(73-98)$ & $87(62-97)$ & 87 (62-97) \\
\hline$s$ PGII $\cdot$ IgG- $H p>241(95 \% \mathrm{CI})$ & $95(84-99)$ & 100 & $92(73-98)$ & $90(68-99)$ & 100 \\
\hline
\end{tabular}

$\mathrm{PPV}=$ Positive predictive values NPV $=$ negative predictive values .

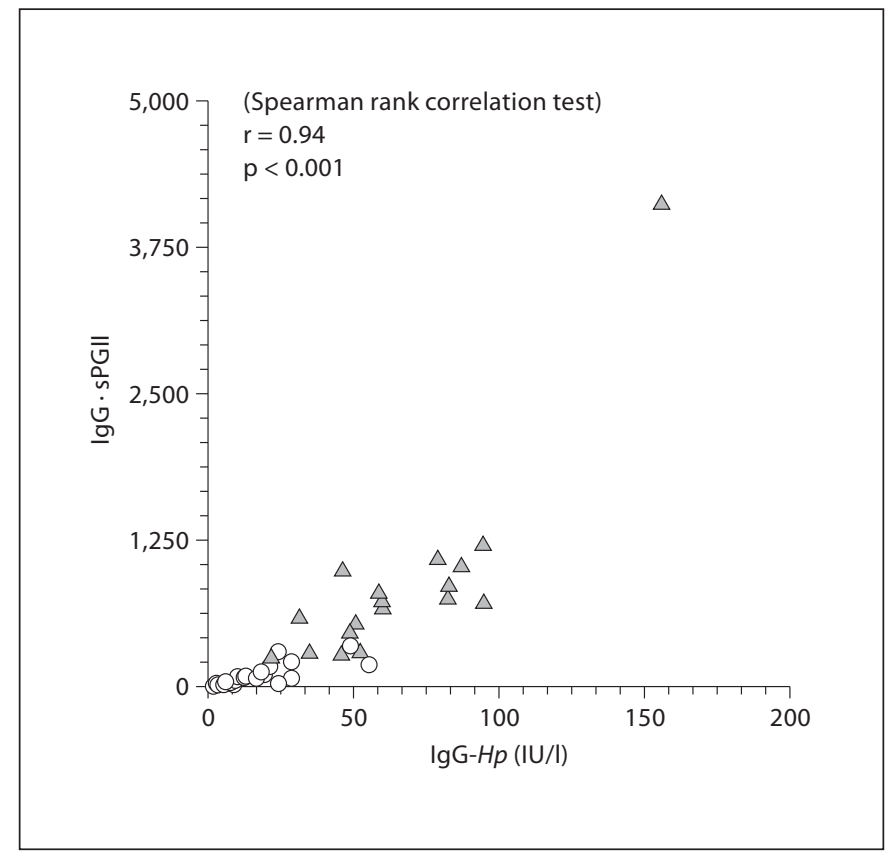

Fig. 2. Distribution of the patients according to both IgG-Hp antibodies and IgG-Hp.sPGII product levels in either H. pylori-positive (triangles) or $H$. pylori-negative children (circles) diagnosed by endoscopy with biopsies.

Determination of the Best Threshold of the Serological Parameters to Diagnose H. pylori Infection

The areas under ROC curves designed by using all possible cut-off levels to discriminate $H$. pylori-positive from $H$. pylori-negative children by means IgG anti- $H$, sPGII and IgG-Hp•sPGII were $0.96,0.91$ and 0.98 , respectively. The most accurate cut-offs level for the detection of $H$. pylori infection were $30 \mathrm{IU} / \mathrm{l}, 9 \mu \mathrm{g} / \mathrm{l}$ and $241 \mathrm{IU} / \mathrm{l} \cdot$ $\mu \mathrm{g} / \mathrm{l}$, respectively, for IgG-Hp, sPGII and IgG•sPGII. The performance characteristics of these cut-offs are summarized in table 3 . The distribution of the patients according to IgG-Hp antibodies and IgG-Hp.sPGII levels as well as
H. pylori status is shown in figure 2. Both sPGI and G-17 had poor areas under receiving operating curves so that their best cut-offs impacted negatively either in sensitivity or specificity of the tests to diagnose $H$. pylori infection and were not reported.

\section{Discussion}

In the present study, $H$. pylori infection and gastric mucosa status, in children with upper gastrointestinal symptoms, were evaluated by means of a serological tests panel, namely sPGI, sPGII, G-17 and IgG-Hp. No child had an important gastroduodenal disease such as gastric or duodenal ulcer, or MALT lymphoma. This is in accordance with the low prevalence of endoscopic features reported in previously studies [7].

The majority of the studied $H$. pylori-positive children (16 out of 18) had the endoscopic picture of the socalled 'antral nodular gastritis', confirming the literature data of the association of this feature with $H$. pylori infection [45]. Among H. pylori-positive patients, those with antral nodular gastritis had both sPGI and sPGII levels increased in comparison to those without. Although both parameters did not reach statistically significant differences, the increase of sPGII levels was, in proportion, more important than sPGI, suggesting a potential association of the first one with this endoscopic feature which is, in turn, frequently related to a more severe $H$. pylori gastritis. However, this result needs to be confirmed with other studies, due to exiguity of the examined sample.

All the patients with $H$. pylori-negative infection had a histologically normal gastric mucosa. Conversely, $H$. pylori-positive children had non-atrophic chronic active gastritis, and 2 also presented with nodular lymphoid hyperplasia. No child resulted in being affected by intestinal metaplasia or atrophy in our cohort. The incidence of the 
latter pathologic features in $H$. pylori-infected children ranges from 0 to $77.7 \%$ in recent studies $[39,41,42]$. We agree with Usta et al. [40] that the relationship between $H$. pylori infection and these lesions in children is not as strong as in adults and their development is influenced by the duration of $H$. pylori infection and environmental and genetic factors.

Very low sPGI levels associated with either low or high G-17 levels are known to be very specific serological patterns of atrophic gastritis [31, 38]; however, due to the absence of this pathologic feature in our cohort, we could not perform any type of inference.

With regard to our H. pylori-positive patients affected by non-atrophic chronic gastritis, both sPGI and sPGII levels increased in comparison to $H$. pylori-negative ones. However, sPGI reached a significant difference only if children $>10$ years were considered. Otherwise, sPGII and IgG-Hp levels were significantly higher in $H$. pyloripositive than in uninfected cases both in children under and over 10 years. However, age could also influence these values, indeed, $H$. pylori-positive children $>10$ years seem to have increased values of both sPGII and IgG-Hp if compared to infected younger ones, although these data were not statistically different. Young children can have an immature response or tolerance to $H$. pylori. In a Japanese study [46] of 157 children, serological determination of IgG- $H p$ was not accurate in patients $<10$ years of age. In the same way, Mégraud et al. [23], investigating the performance characteristics of four non-invasive tests in a cohort of 503 children (UBT, stool antigen test, and antibody detection in serum and urine), observed a trend for an improved sensitivity with increased age for all tests except the stool antigen test. For unknown reasons (probably related to a less inflammatory response in the low class of age), this behavior also seems to be the case for serum pepsinogens (especially for sPGI).

Both IgG-Hp and serum pepsinogen levels are influenced by the presence of $H$. pylori infection, but they follow different routes and can be considered as two different tests. IgG-Hp values are related to the efficacy of the immunological humoral response and are markers of exposure to the bacterium. On the other hand, increased values of both sPGII and sPGI are the consequence of $H$. pylori-induced altered gastric secretion. Intramucosal peptic activity both in antrum and corpus could be inhibited by the presence of the bacterium, determining a backflow of pepsinogens into the circulation [47, 48]. Furthermore, among $H$. pylori-positive children, those carriers of more cytotoxic $H$. pylori strains can have more increased serum pepsinogen levels [49]. Investigat-

Serological Panel Test in the Assessment of Gastritis in Symptomatic Children ing the role of Cag-A and Vac-A on the serological levels of gastrin and pepsinogens in $51 \mathrm{H}$. pylori-positive children, Kim and Chung [33] observed a significant increase of pepsinogen levels in Cag-A-positive than CagA-negative children but not of gastrin. Interestingly, sPGII levels, but not sPGI, were significantly higher in patients with both Cag-A- and Vac-A-positive than both Cag-A- and Vac-A-negative ones, showing a more susceptible increase of sPGII in the presence of the most cytotoxic strains.

In our findings, with regard to $H$. pylori-positive patients, sPGII levels resulted in being proportionally higher than sPGI. A mere consequence of this matter was the significant decrease of the sPGI/sPGII ratio. The difference between sPGI and sPGII could be explained by the gastric site of constitution; the first one is produced only in the corpus glands, while the latter in both the antrum and corpus, and consequently relating to gastric inflammation independently of its localization. In our previous study, indeed, performed in $70 \mathrm{H}$. pylori-positive dyspeptic adult patients [35], sPGII increased significantly in comparison to $H$. pylori-negative ones and successful $H$. pylori eradication was followed by a significant reduction of both of these parameter levels and gastric mucosa neutrophilic infiltration.

Oderda et al. [32] reported increased sPGI levels in $H$. pylori-positive in comparison to $H$. pylori-negative children. However, in this work the effects of age were not considered, sPGII was not measured and sPGI was analyzed with a different method (radioimmunoassay), so it is difficult to compare this result with our data. The same authors reached by means of sPGI both $71 \%$ of sensitivity and specificity to diagnose $H$. pylori infection. Interestingly, using the combined results of sPGI and IgG-Hp antibodies, very good sensitivity and specificity for $H$. pylori detection (up to 95\%) was reached.

In our results, both sPGI and G-17 did not have a satisfactory accuracy to diagnose $H$. pylori infection. Conversely, very good performance characteristics were achieved with both IgG-Hp antibodies and sPGII, after their best cut-offs (which differed from adults) were calculated. However, the combination of these two parameters in the product ameliorated the performance. In fact, IgG-Hp·sPGII reached both an excellent sensitivity and negative predictive value ( 0 false-negative). In this way, it can overcome the false-negative results related to a decreased maturity of the immune system in very young patients. If this parameter is normal, there is in fact a strong probability that patients have a healthy gastric mucosa. However, in case of positive IgG-Hp•sPGII, due to 
the two false-positives related to this parameter, it is important to also analyze both IgG-Hp and sPGII levels singularly. From a practical point of view, if both sPGII and IgG-Hp are over the cut-off, the patients should be considered $H$. pylori-positive. In case of high sPGII but low IgG-Hp levels, the patients should be affected by nonH. pylori-related gastritis. Otherwise (high IgG-Hp and low sPGII levels), the patient should be previously infected and healed.

In summary, serological parameters such as sPGI and sPGII, G-17 and IgG-Hp could be useful as a first approach in the pediatric management of children with upper gastrointestinal symptoms. Although other non-invasive tests such as C-13 UBT or $H$. pylori stool antigen reach an excellent sensitivity $[21,28,45]$ to diagnose $H$. pylori infection, the serological panel of tests could give information on various aspects of gastric mucosa, beside H. pylori infection. Low sPGI and either low or high G-17 could permit to exclude the presence of rare conditions such as gastric atrophy or antral gastrin cell hyperfunction [50]. On the other hand, increased sPGII levels could suggest a pattern of non-atrophic gastritis. Furthermore, the cross-combination of IgG-Hp.sPGII product and IgG-Hp antibodies can reliably diagnose or exclude the presence of $H$. pylori chronic gastritis. These non-invasive serological tests are less stressful for children if compared to endoscopy or UBT, and could be proposed in the initial management of children with upper gastrointestinal symptoms as well as in monitoring $H$. pylori eradication, if the satisfactory result observed in adults [35] will be extended in children. These results need to be confirmed in a larger cohort, also stratifying children in different age classes in order to perform the appropriate cutoff parameters before recommending their widespread clinical application as non-invasive first-pass markers of gastric disease in a pediatric population.

\section{References}

1 Blaser MJ, Chyou PH, Nomura A: Age at establishment of Helicobacter pylori infection and gastric carcinoma, gastric ulcer, and duodenal ulcer risk. Cancer Res 1995;5:562565.

$\checkmark 2$ Drumm B, Day AS, Gold B, et al: Helicobacter pylori and peptic ulcer: working group report of the second world congress of pediatric gastroenterology, hepatology, and nutrition. J Pediatr Gastroenterol Nutr 2004; 39:S626-S631.

$>3$ Chong SKF, Lou Q, Zollinger TW, et al: The seroprevalence of Helicobacter pylori in a referral populations of children in the United States. Am J Gastroenterol 2003;98:21622168.

4 Elitsur Y, Short JP, Neace C: Prevalence of Helicobacter pylori infection in children from urban and rural West Virginia. Dig Dis Sci 1998;43:773-778.

$\checkmark 5$ Malfertheiner P, Mégraud F, O’Morain C, Hungins APS, Jones R, Axon A, Graham DY, Tytgat $\mathrm{G}$ and The European Helicobacter pylori Study Group (EHPSG): Current concepts in the management of Helicobacter pylori infection - The Maastricht 2-2000 Consensus Report. Aliment Pharmacol Ther 2002;16:167-180.

6 Gold BD, Colletti RB, Abbott M, et al: Helicobacter pylori infection in children: recommendations for diagnosis and treatment. J Clinical Microbiol 2000;31:490-497.

7 Drumm B: Helicobacter pylori in the pediatric patient. Gastroenterol Clin North Am 1993;22:169-182. $\checkmark 8$ Suerbaum S, Michetti P: Helicobacter pylori infection. N Engl J Med 2002;347:11751186.

$\checkmark 9$ Imrie C, Rowland M, Bourke B, Drumm B: Helicobacter pylori in childhood, a risk for gastric cancer? Pediatrics 2001;107:373-380.

10 Macarthur C, Saunders N, Feldman W, et al: Helicobacter pylori and childhood recurrent abdominal pain: community based-control study. Br Med J 1999;319:822-823.

$\checkmark 11$ Wewer V, Kalach N: Helicobacter pylori infection in pediatrics. Helicobacter 2003; 8(suppl 1):61-67.

12 Nijevitch AA, Scherbakov PL: Helicobacter pylori and gastrointestinal symptoms in school children in Russian. J Gastroenterol Hepatol 2004;19:490-496.

13 Kalach N, Mention K, Guimber D, et al: Helicobacter pylori infection is not associated with specific symptoms in nonulcer-dyspeptic children. Pediatrics 2005;115:17-21.

14 Drumm B, Koletzko S, Oderda G: Helicobacter pylori infection in children: a consensus statement. European Paediatric Task Force on Helicobacter pylori. J Pediatr Gastroenterol Nutr 2000;30:207-213.

15 Jones NL, Sherman P, Fallone CA, et al: Canadian Helicobacter pylori Group Consensus Conference: Update on the approach to $\mathrm{He}$ licobacter pylori infection in children and adolescent - an evidence-based evaluation. Can J Gastroenterol 2005; 19:399-408.

16 Crabtree JE, Mahony MJ, Taylor JD, et al: Immune responses to Helicobacter pylori in children with recurrent abdominal pain. J Clin Pathol 1991;44:768-771.
Czinn SJ: Serodiagnosis of Helicobacter $p y$ lori in pediatric patients. J Pediatr Gastroenterol Nutr 1999;28:132-134.

18 Andersen LP, Wewer AV, Christiansen KM, et al: The humoral immune response to $\mathrm{He}$ licobacter pylori in children with recurrent abdominal pain. APMIS 1994;102:457-464.

19 Perri F, Pastore M, Clement R, et al: Helicobacter pylori infection may undergo spontaneous eradication in children: a 2-year follow-up study. J Pediatr Gastroenterol Nutr 1998;27:181-183.

20 Oderda G, Vaira D, Ainley C, et al: Eighteen month follow-up of Helicobacter pylori-positive children treated with amoxycillin and tinidazole. Gut 1992;33:1328-1330.

21 Oderda G, Rapa A, Ronchi B, et al: Detection of Helicobacter pylori in stool specimens by non-invasive antigen enzyme immunoassay in children: multicentre Italian study. BMJ 2000;320:347-348.

-22 Koletzko S, Konstantopoulos N, Bosman D, et al: Evaluation of a novel monoclonal enzyme immunoassay for detection of Helicobacter pylori antigen in stool from children. Gut 2003;52:804-806.

23 Mégraud F on behalf of the European Pediatric Task Force on Helicobacterpylori: Comparison of non-invasive tests to detect Helicobacter pylori infection in children and adolescents: results of a multicenter European study. J Pediatr 2005;146:198-203.

24 Elitsur Y: Helicobacter pylori diagnostic tools: Is it the stool? J Pediatr 2005;146:164167. 
25 Cutler AF, Havstad S, Ma CK, et al: Accuracy of invasive and non-invasive tests to diagnose Helicobacter pylori infection. Gastroenterology 1995;109:136-141.

26 Bazzoli F, Cecchini L, Corvaglia L, et al: Validation of the ${ }^{13} \mathrm{C}$-urea breath test for the diagnosis of Helicobacter pylori infection in children: a multicenter study. Am J Gastroenterol 2000;95:646-650.

-27 Kindermann A, Demmelmair H, Koletzko $\mathrm{B}$, et al: Influence of age on ${ }^{13} \mathrm{C}$-urea breath test results in children. J Pediatr Gastroenterol Nutr 2000;30:85-91.

28 Hino B, Eliakim R, Levine A, et al: Comparison of invasive and non-invasive tests diagnosis and monitoring of Helicobacter pylori in children. J Pediatr Gastroenterol Nutr 2004;39:519-523.

29 Samloff IM, Varis K, Ihamàki T, et al: Serum pepsinogens I and II and gastric acid output: effect of gastritis; in Clinical and Genetic Advances. New York, Liss, 1985.

30 Plebani M, Basso D, Cassaro M, et al: Helicobacter serology in patients with chronic gastritis. Am J Gastroenterol 1996;91:954-958.

-31 Germaná B, Di Mario F, Cavallaro LG, et al: Clinical usefulness of serum pepsinogens I and II, gastrin-17 and anti-Helicobacter pylori antibodies in the management of dyspeptic patients in primary care. Dig Liver Dis 2005;37:501-508.

32 Oderda G, Vaira D, Holton J, et al: Serum pepsinogen I and IgG antibody to Campylobacter pylori in non-specific abdominal pain in childhood. Gut 1989;30:912-916.

33 Kim JW, Chung KS: Serum gastrin and pepsinogen I, II concentration in children with Helicobacter pylori infection: the role of CagA and VacA. Yonsei Med J 1998;39:159165.
34 Plebani M, Di Mario F, Stangehellini V, et al: Serological test to monitoring treatment of Helicobacter pylori. Lancet 1992;340:51-52.

35 Di Mario F, Moussa AM, Cavallaro LG, et al: Clinical usefulness of serum pepsinogen II in the management of Helicobacter pylori infection. Digestion 2004;70:167-172.

36 Oderda G, Vaira D, Dell'Olio D, et al: Serum pepsinogen I and gastrin concentrations in children positive for Helicobacter pylori. J Clin Pathol 1990;43:762-765.

37 Araki H, Miyazaki R, Matsuda T, et al: Significance of serum pepsinogens and their relationship to $H$. pylori infection and histological gastritis in dialysis patients. Nephrol Dial Transplant 1999;14:2669-2675.

38 Sipponen P, Ranta P, Helske T, et al: Serum levels of amidated gastrin-17 and pepsinogen I in atrophic gastritis: an observational casecontrol study. Scand J Gastroenterol 2002;37: 785-791.

-39 Cohen MC, Cueto Rua E, Balcarce N, et al: Assessment of the Sydney system in Helicobacter pylori-associated gastritis in children. Acta Gastroenterol Latinoam 2000;30:3540.

40 Usta Y, Saltik-Temizel IN, Ozen H: Gastric atrophy and intestinal metaplasia in Helicobacter pylori infection. J Pediatr Gastroenterol Nutr 2004;38:548.

41 Guarner J, Bartlett J, Whistler T, et al: Can pre-neoplastic lesions be detected in gastric biopsies of children with Helicobacter pylori infection? J Pediatr Gastroenterol Nutr 2003; 37:309-314.
42 Ozturk Y, Buyukgediz B, Arslan N, et al: Antral glandular atrophy and instestinal metaplasia in children with Helicobacter pylori infection. J Pediatr Gastroenterol Nutr 2003; 37:96-97.

43 Kalach N, Legoedec J, Wann AR, et al: Serum levels of pepsinogen I, pepsinogen II, and gastrin-17 in the course of Helicobacter pylori gastritis in pediatrics. J Pediatr Gastroenterol Nutr 2004;39:568-570.

44 Dixon MF, Genta RM, Yardley JH, et al: Classification and grading of gastritis. The Updated Sydney System. Am J Surg Pathol 1996;20:1161-1181.

45 Kato S, Ozawa K, Koike T, et al: Effect of $\mathrm{He}$ licobacter pylori infection on gastric acid secretion and meal-stimulated serum gastrin in children. Helicobacter 2004;9:100-105.

-46 Okuda M, Miyashiro E, Koike M, et al: Serodiagnosis of Helicobacter pylori infection is not accurate for children aged below 10. Pediatr Int 2002;44:387-390.

47 Yahav J, Oderda G, Diver-Haber A, et al: Mucosal peptic activity during Helicobacter pylori infection in pediatric patients. Gut 1992; 33:1162-1165.

48 Yahav J, Oderda G, Diver-Haber A, et al: Serum pepsinogen I in childhood Helicobacter pylori gastritis: its relation to mucosal peptic activity. Isr J Med Sci 1996;32:56-59.

49 Fukuda Y, Isomoto H, Ohnita K, et al: Impact of CagA status on serum gastrin and pepsinogen I and II concentrations in Japanese children with Helicobacter pylori infection. J Int Med Res 2003;31:247-252.

50 Rindi G, Annibale B, Bonamico M, et al: $\mathrm{He}$ licobacter pylori infection in children with antral gastrin cell hyperfunction. J Pediatr Gastroenterol Nutr 1994;18:152-158. 